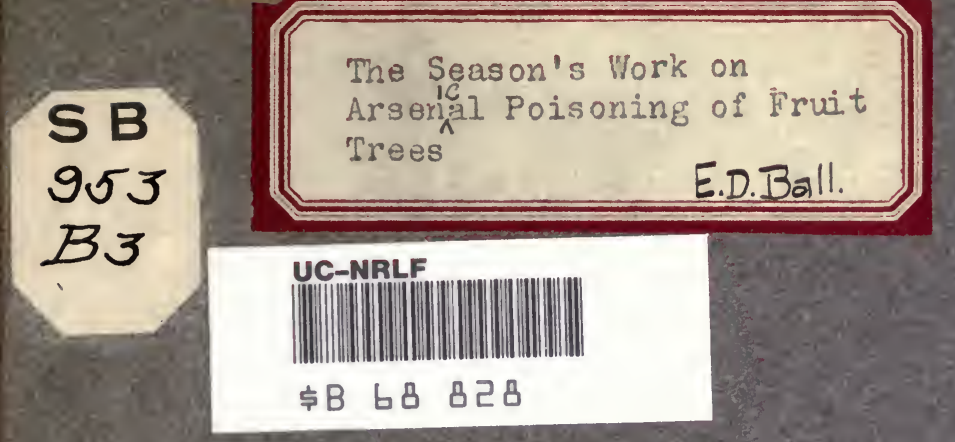







[Reprinted from the Journal of Economic Entomology, Vol. 3, No. 2, 1910]

Compliments of the Authors

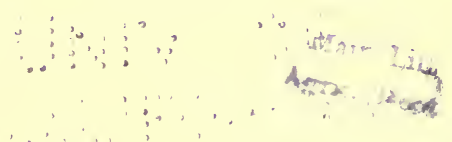

\section{THE SEASON'S WORK ON ARSENICAL POISONING OF FRUIT TREES}

By E. D. Ball, E. G. Titus and J. E. Greaves, Utah Experiment Station, Logan

As was suggested in a former paper ${ }^{1}$ by the senior author, the determination of the effect of arsenical spraying on the life of our fruit trees is a problem of immense importance to the fruit interests of the country. The immediate solution of the problem is, however, of most vital importance to the western fruit growing sections as it is in these sections that the greatest amount of planting is now being done, a planting that would not be justified if the profits of orcharding are likely to be curtailed as has been recently suggested. ${ }^{2}$

It has, therefore, seemed advisable to present at this time a brief, preliminary report of the results of the investigations carried on by the Utah Experiment Station during the season of 1909.

\section{Work of the Season}

The season's work consisted of a study of the orchard and soil conditions in all of the principal apple producing sections west of the Rocky Mountains, together with various field and laboratory experiments to determine the effect of different strengths of arsenical compounds and different methods of application on plant growth. The study of western fruit conditions was mainly preliminary in nature and was undertaken with a view of determining the actual extent of the injury and to discover, if possible, the most favorable locations for the inauguration of detailed experiments. The experiments undertaken were also largely preliminary in nature and for the purpose

${ }^{1}$ Ball, Jl. Ec. Ento., 2, p. 143, 1909.

${ }^{2}$ Headden, Jl. Ec. Ento., 2, p. 245, 1909. 
of mapping out the problem and determining methods of approach.

No single line of investigation was carried on long enough or thoroughly enough to warrant definite conclusions from this line of evidence alone. The results of the different lines undertaken, however, were in such close agreement with reference to the general principles involved, that taken together the results were very significant and seemed to warrant this preliminary publication.

It might be wels the nite in the connection that on account of the serious and lasting nature of the pear blight injury to the larger portion of the pear srehards of the inter-mountain region, and the impossibility of separating this injury from that of other causes, that the investigation was confined to the problem as presented in the apple orchards.

\section{A Study of Western Orchard Regions}

In the investigation of orchard regions a study was made of the more typical orchard soils especially with reference to their alkali content and general seepage conditions. Two or more of the oldest and longest sprayed of the commercial orchards located in each of the typical orchard regions were usually chosen and thoroughly investigated. On these orchards soil borings were made to ascertain depth of soil and distance to ground water and for chemical analysis. Samples of surface soil were collected to study the deposition of arsenic and samples of the trees taken to study its accumulation in the trees. In each of the orchards, the number of sprayings applied and the amount and kind of poison used were ascertained where possible. These orchards were taken as representatives of the better orchard conditions. In each valley at the same time, an attempt was made to ascertain the places where the greatest losses of trees were taking place and the conditions under which they occurred were investigated. Owing to sickness, the chemical investigations of this part of the work have not been completed and it is impossible at this time to give the detailed statement of the chemical findings.

It is hardly necessary to call attention to the fact that even under the most favorable environment there is an occasional loss of a tree through accident or individual weakness, and that even more frequently trees are permanently injured, especially in the region of the crown, through the ordinary processes of orchard cultivation.

The Pajaro Valley in California is the principal apple shipping section of that state. The soils are deep and range from loamy to heavy adobe. No irrigation water is used and no indication of alkali or of seepage conditions could be found in the principal orchard dis- 
trict. The orchard of Mr. C. H. Rogers of Watsonville was chosen for investigation as being the oldest and longest sprayed of the commercial orchards. Spraying has been carried on in this valley for seven years and the average number of sprayings applied has been about four. Nowhere in the valley was evidence seen of injury to the trees of any kind other than accidental.

The Rogue River Valley of southern Oregon has a similar soil and uses very little irrigation water. No traces of alkali were seen except for a very slight spot in the lowest portion of the valley and the scarcity of water prevents the possibility of seepage conditions. The Burrell and Bear Creek orchards are two of the oldest in the Medford district and have been sprayed for a number of years, ever since spraying was undertaken in the valley. No injury could be found on any of the trees in these orchards or in any others examined except for the small alkali spot before mentioned, in which a few young Newtons that had never been sprayed, were dying.

In the Hood River Valley the soil is much lighter, consisting of volcanic ash, and little water is used, the orehardists depending very largely upon the excellence of their soil mulch, as they are compelled to do in the Rogue River Valley. No traces of alkali were seen in this valley and seepage is almost unknown, being eonfined to small and isolated spots in which the character of the injury is perfectly evident. No injury that could in any way be attributed to the effect of arsenic was found in this valley. Two of the oldest commercial orchards, those of Sears and Porter and of Chriss Dethman, were examined carefully. One had been sprayed for twelve years and the other for considerably longer, both of them heavily, as is the usual manner in Hood River, but without any apparent injury to the trees.

The Wenatchee Valley in Washington is one of the younger orchard valleys, but is already experiencing some trouble. In a number of places trees were seen dying of apparently typical cases of collar rot and often the last tree in the row, where the water had been allowed to stand was found to be dying or dead. They suffered somewhat from sunscald one season several years ago and the injury is still noticeable on many of the older trees, but wherever the trees were found to be dead or dying without showing the sunken area at the base, the evidence of excess of water, together with traces of alkali along the edges of the furrows where the water had stood, was always in evidence and where the collar rot condition was the most prevalent, brownish or whitish margins were present along the irrigation furrows and these areas were quite damp and sticky at the time the writer visited this section. Mr. Z. A. Lanhan's orchard and that of Mr. P. 
P. Holcomb are among the oldest of the typical commercial orchards and have been sprayed rather heavily until recently. They do not, however, show as much indication of the trouble as many of the orchards which have been sprayed less and are located under less favorable soil conditions.

The Yakima Valley is located on the Snake River some distance below Wenatchee and like its sister valley has a variety of soils and a considerable amount of hardpan and seepage lands. Mr. William Richards has sprayed his orchard eleven years, six or seven times per year. Gibson Brothers, on similar soil, have been spraying for the same length of time. These orchards are both of them above the danger of seepage and very slight traces of alkali were visible and as far as they were observed, the orchards have not suffered in any way from their spraying. Mr. W. I. Huxtable's orchard which is on the higher lands of Knob Hill, was investigated and a white, impenetrable hardpan was encountered at about four feet, which seemed to be characteristic of the soils of this region. The trees in this section showed no apparent injury but on some of the older orchards the leaves were slightly yellow and the fruit small, indicating a lack of soil fertility. That it could not be due to any effect of the arsenic applied was evident from the fact that the same condition was observed on both apple and peach orchards. At a little lower level than this a large number of young trees just coming into bearing were observed to be dead or dying. Most of the trees affected were Spitzenbergs, and many of them had never been sprayed. In every case, however, the dead trees were found on the lower sides of the orchards where the irrigation water had been allowed to bank up against the roadway or ditch bank. In many of these places the ground showed unmistakable traces of alkali and the condition was apparently growing worse as the newer orchards showed only slight traces of it. It seemed probable that unless more care was used in handling the irrigation water in the future, considerable areas would be injured in this way.

A Ben Davis orchard was seen in this section that had been irrigated very late in the fall and as a result, almost every tree had been winter killed on the southwest side, the injury extending in some cases even to the upper sides of the limbs extending toward the northeast. This was the most severe case of scalding that has been observed and was considered to be caused by arsenical spraying until attention was called to the fact that every single tree was injured on the southwest side.

The Payette-Boise Valleys in Idaho are the largest apple producers and like other Snake River valleys, have considerable amounts 
of hardpan at varying depths. These valleys are older than those in the lower Snake River district and the seepage conditions have grown worse from year to year until now large parts of a number of orchards on the lower levels, have been killed by alkaline ground water. On the higher levels the soil shows traces of alkali, but where the drainage is good no injury as yet has appeared on the trees. The orchards of Capt. J. H. Shawhan and of Bower and Hunter near Payette, of Hon. Edgar Wilson at Meridian, and Judge Fremont Woods near Boisé, were studied as typical of the better class of orchard soils in these valleys. These orchards have all been heavily sprayed for a number of years, representing the oldest of the commercial orchards in their districts and those that have received the greatest amount of spraying and yet they showed no sign of any injury attributable to that cause. These orchards all show distinct traces of alkali and it would seem to be a favorable condition for arsenic injury, if such occurs.

In Utah a number of new orchards have been examined in which Ben Davis and Gano trees are dying of collar rot, the greater number of them, however, being cases occurring in family orchards and on town lots where no spraying has ever been done. In Mr. Lars Nording's orchard at Hyrum, five Black Ben Davis trees, planted five years ago, began to die this season. This was the first season that they had borne and only one of them was sprayed, and even at the time that the spray was applied, the characteristic darkened area with oozing sap was seen at the base of the trees.

In the Grande Valley in Colorado a number of orchards pointed out as being typical cases of arsenical poisoning were examined, and in every case except one, unmistakable seep conditions were encountered within five to seven feet of the surface and in some cases even closer. Mr. F. T. Smith's orchard was typical of this class of orchards and in this case a considerable area showed a decided burning of the leaves in the early part of the summer. Mr. Smith reported that upon examination, at that time, he found the soil to be very dry and free from seepage conditions to a depth of six feet. When bored with a nine-foot augur later in the summer, the first six feet were found to be as dry as before but before reaching the seventh foot, the augur sank of its own weight into a soft, sticky ooze that extended as far as the augur would reach. In another place in which a strip had died near one end of an orchard, a soil boring made at the same time, only proceeded a little over two feet before the augur could be pushed clear down to the handle in a material similar to that found before. Mr. M. P. Hickman's orchard which was upon one of the higher mesas 
and is claimed by other investigators to be free from alkali troubles, was the only exception to the finding of definite seep conditions and even in this orchard the second and third foot were found to be sandy and very wet and at the eighth foot another layer of wet sand was encountered. Along the edges of this orchard the alkali showing was quite marked and in an oblique strip running through the orchard in which most of the trees had died, some of them with rather typical collar rot conditions, the sides of the irrigation furrows showed unmistakable traces of alkali. It was also noticed that a crop of weeds had sprung up in the area where the trees were affected while the remaining portions of the orchard were quite bare, the cultivation having been the same throughout, indicating that the rising ground water had been sufficient to germinate seeds in the affected areas.

The orchard formerly owned by Dr. F. R. Smith is one of the oldest orchards in this valley and is located on top of one of the fruit ridges. This orchard is twenty-three years old and has receivcd one hundred and eight heavy sprayings, perhaps the greatest amount of arsenic that has been applied to any orchard in this western country. As Doctor Smith relates, he sprayed until the water ran down the trees and saturated the bands, soaking the ground. For five years he used the Kedzie formula double strength and sprayed seven times a season. The orchard shows no indication of having been injured in any way by this excessive amount of spraying. This amount of poison is far more than would be necessary to protect a tree for its entire life under present methods of application: There is no sign of alkali in any part of this orchard, lying as it does on the crest of a narrow ridge, and in this orchard there seems to be the ideal condition for testing the possible effect of arsenic when free from the contaminating influence of alkaline waters, and as yet there is no evidence of injury. In fact, the orchard is in a remarkably healthy condition with the exception of one tree which is subject to overflow from a nearby ditch.

In the Delta-Montrose District a number of orchards which were pointed out as being affected by arsenical poisoning, were studied. Nearly all of the orchards of this section are located upon high mesa lands. The soils on the surface are usually fertile but vary considerably in depth. On boring, the soil augur usually encounters a calcareous hardpan, or "marl" layer, as it is called, at from eighteen inches to three or more feet from the surface. This layer is from one to two feet in thickness and is often penetrated by the roots of the trees. Throughout this entire district the Jonathan apples are more or less affected and in some orchards a considerable number have 
died. Mr. L. W. Sweitzer's orchard, near Delta, presents a typical case of this kind. The Jonathans are becoming affected in small groups, while the blocks of Winesap, Gano and Black Twig are apparently uninjured. Upon examining the soil in the places where the Jonathans were dying, it was found that in every case the marl was near the surface in these areas, so near that oftentimes it would be pulled up with the roots of the trees. As has been noted by previous writers $^{3}$ when large limbs are sawed off from affected trees, they contime to bleed and deposit large masses of calcareous material. It is possible that the excess of this material in the sap is the cause of the trouble, but whatever it is, the Jonathan seems to be practically the only tree that is affected in this region, the Ganos in this same orchard being very healthy. Located as these orchards are on rather high and well drained mesa land, there is little trouble from alkali or seepage. The Ashenfelter orchard near Montrose is located upon a mesa in which this marly layer is particularly close to the surface and here the condition of the trees suggests a lack of fertility in the soil. This condition was apparent in this particular orchard before it came into bearing, and, therefore, before sprays were applied. This condition has been referred to as systemic arsenical poisoning.

Summary of Orchard Investigations: It will be seen from the above descriptions that in the regions like the Pajaro Valley, the Rogue River and Hood River Valleys, where little or no irrigation water is used, and where if anything the orchards suffer from lack of water, and the soils are comparatively free from alkali, the troubles under consideration are entirely unknown.

That in every district in which the alkali is present in sufficient amounts to appear on the surface and where water is sufficiently abundant to cause seepage in the lower districts, that more or less of these root rot or collar rot conditions occur. In bad cases of seepage whole orchards are stricken within a year or two, oftentimes after they have borne a number of heavy crops. This may be due to a gradual rise of the ground water, or to the gradual extension downward of the roots of the trees. In milder cases, only here and there a tree is affected and these often linger along for a number of years, sometimes in a dry year, partially recovering, only to be stricken again in a wet one. If there is any perceptible slope to the ground the trouble will usually be more marked on the lower end of the irrigation furrows. Where alkali is evidently the eause of the death of the trees, no variety seems to be exempt, all being equally affected.

${ }^{3}$ Headden, Col. Exp. Sta. Bull. 131, p. 25, '08. 
In a number of the higher valleys of Utah in which there is very little trace of alkali but where oftentimes the ground water is close to the surface, the apple trees of the Ben Davis and Gano varieties suffer from a condition which is commonly known as "collar rot." These trees often linger along for many years, new areas at the crown dying and then gradually healing over as the tree recovers, only to die in a new or larger area at a later date. This trouble seems to be almost exclusively confined to the Ben Davis-Gano type of tree and is occasionally met with throughout most of the apple growing regions. The real cause of this condition is still in doubt. It is usually first noticed just above the surface of the ground as a darkened area of bark which often exudes a few drops of a darkcolored, gummy liquid which later dries, and as the tree grows, this spot becomes a sunken area from which the bark gradually rots away.

The Grande Valley offers by far the worst case of seepage injury to be found in the western country. As the water has been taken out onto the upper lands, the lower ones have gradually been destroyed by the rising water. Hundreds of acres of orchard have already died and been removed and hundreds more are now more or less affected. Here, as everywhere else, the alkali condition is no respecter of variety or age. Every kind of a tree that occurs in the path of the seepage areas is killed and many young orchards of only one or two years' growth are dying. In fact, during the past season more trees under the bearing age were killed than were those above that age. It has been claimed that the higher regions, especially the mesas, were above the possibility of seepage, but this season has abundantly demonstrated that even these regions are not entirely exempt, as yearling trees on soil which has never grown apples before were killed in considerable numbers by white alkali within a few rods of the top of one of the best fruit ridges, as is shown in an accompanying photograph. With this picture in mind it is easy to see how it would be possible for trees to be killed by seepage on any of the adjoining mesas of similar elevation. There may be, and probably is, a small amount of the collar rot condition as found in Utah, present on some of these higher lands since the Ben Davis and Gano in certain sections seem to suffer more than other varieties. But it seems a rather peculiar logic to reason that these varieties are dying from arsenical poisoning in a valley where Jonathans are scarcely affected, and in the case of the very next valley to account for the death of a large number of Jonathans by arsenical poisoning where Ben Davis and Gano are not affected. 
Plate 1:

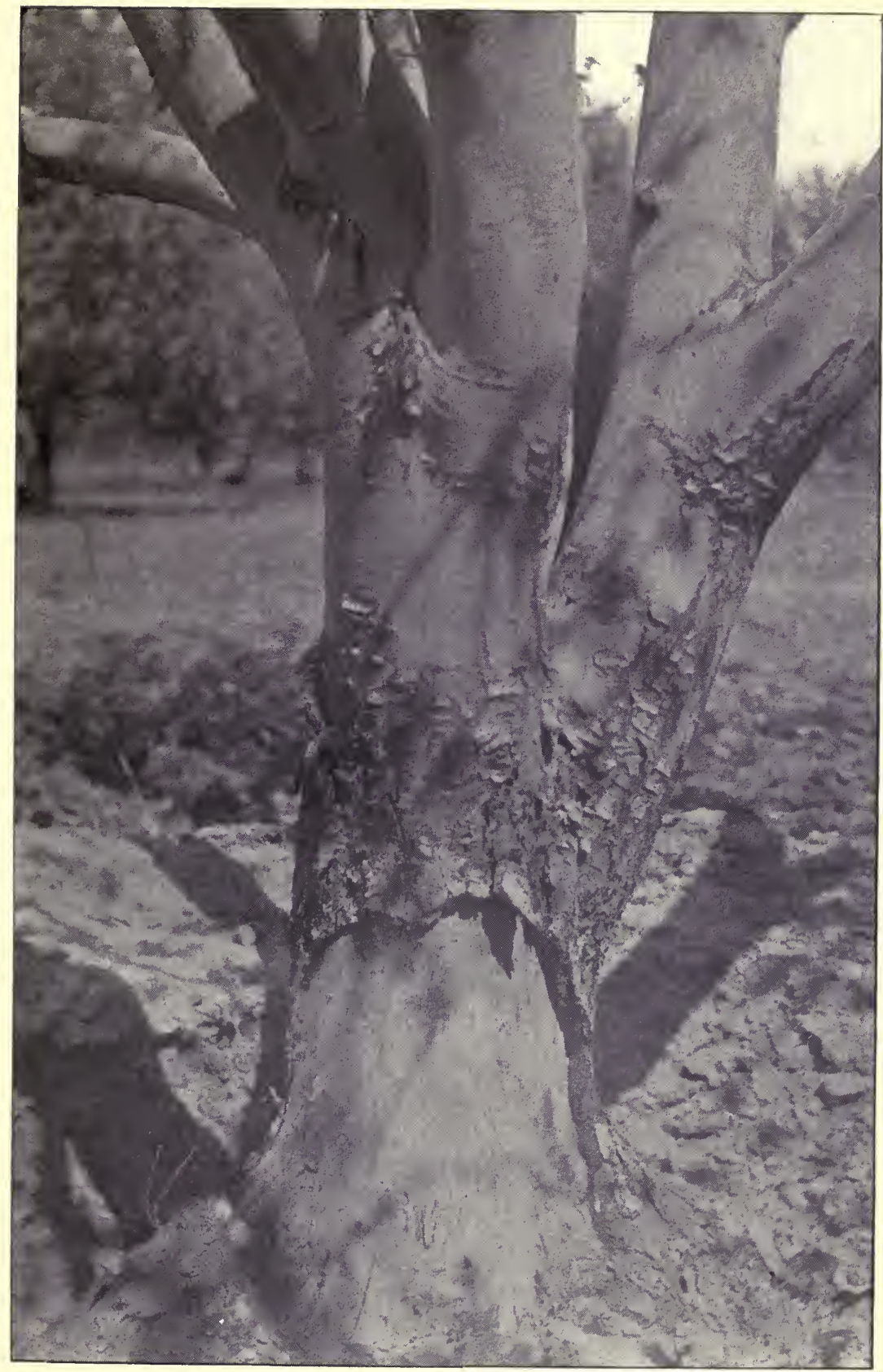

A bad " collar rot " case showing a partial recovery and growing over on one side. Notice the dead bark above and on the left side 




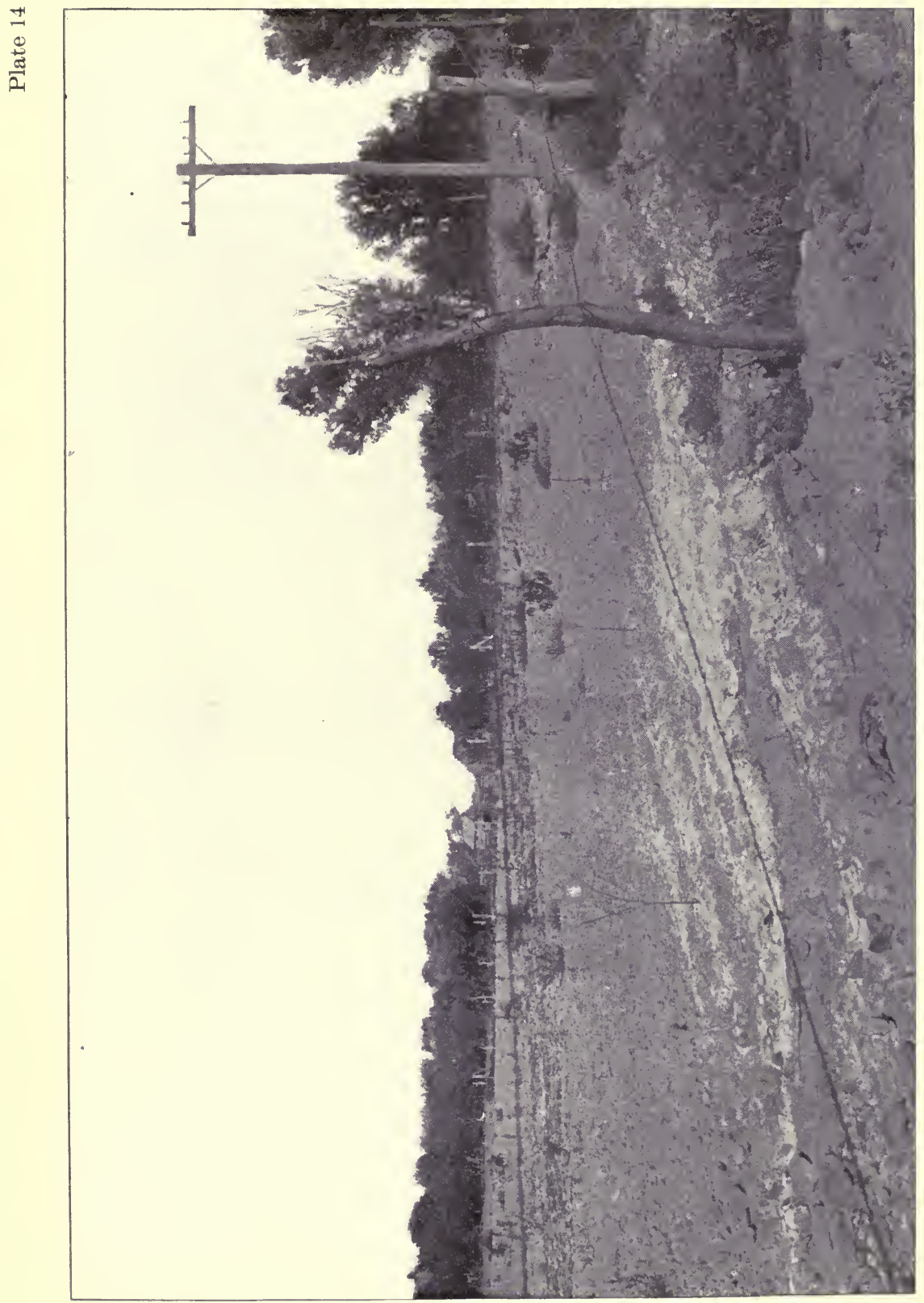

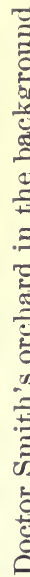

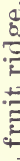

4

。

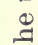

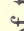

क्

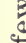

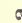

.

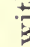

$\Phi$

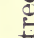

吾

웅

章 

2

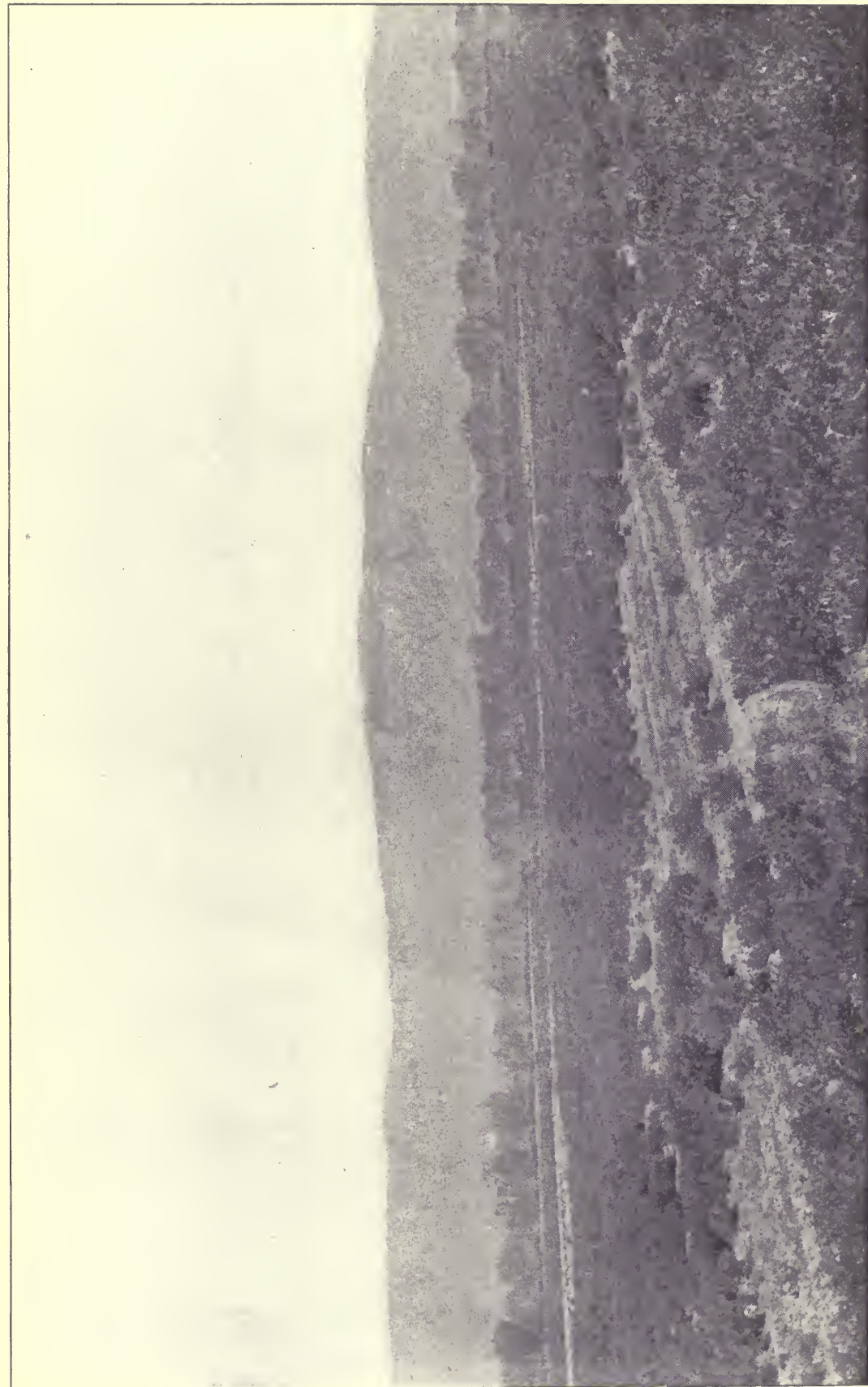





$\underset{\substack{\infty \\ \frac{\infty}{\infty}}}{\stackrel{\infty}{1}}$

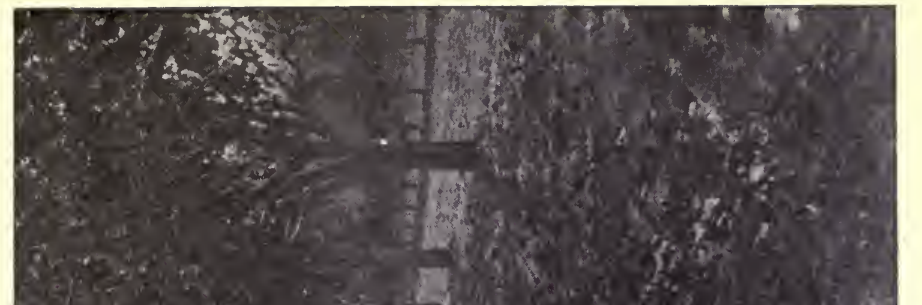

造

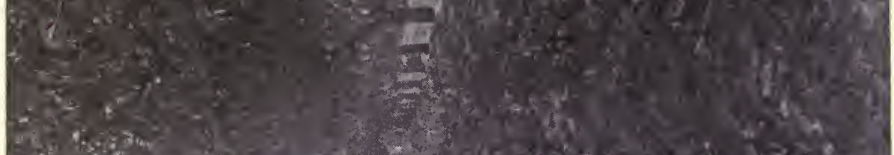

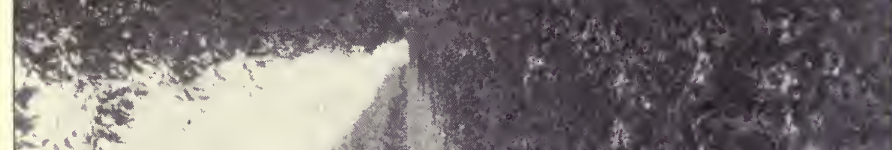

kis is
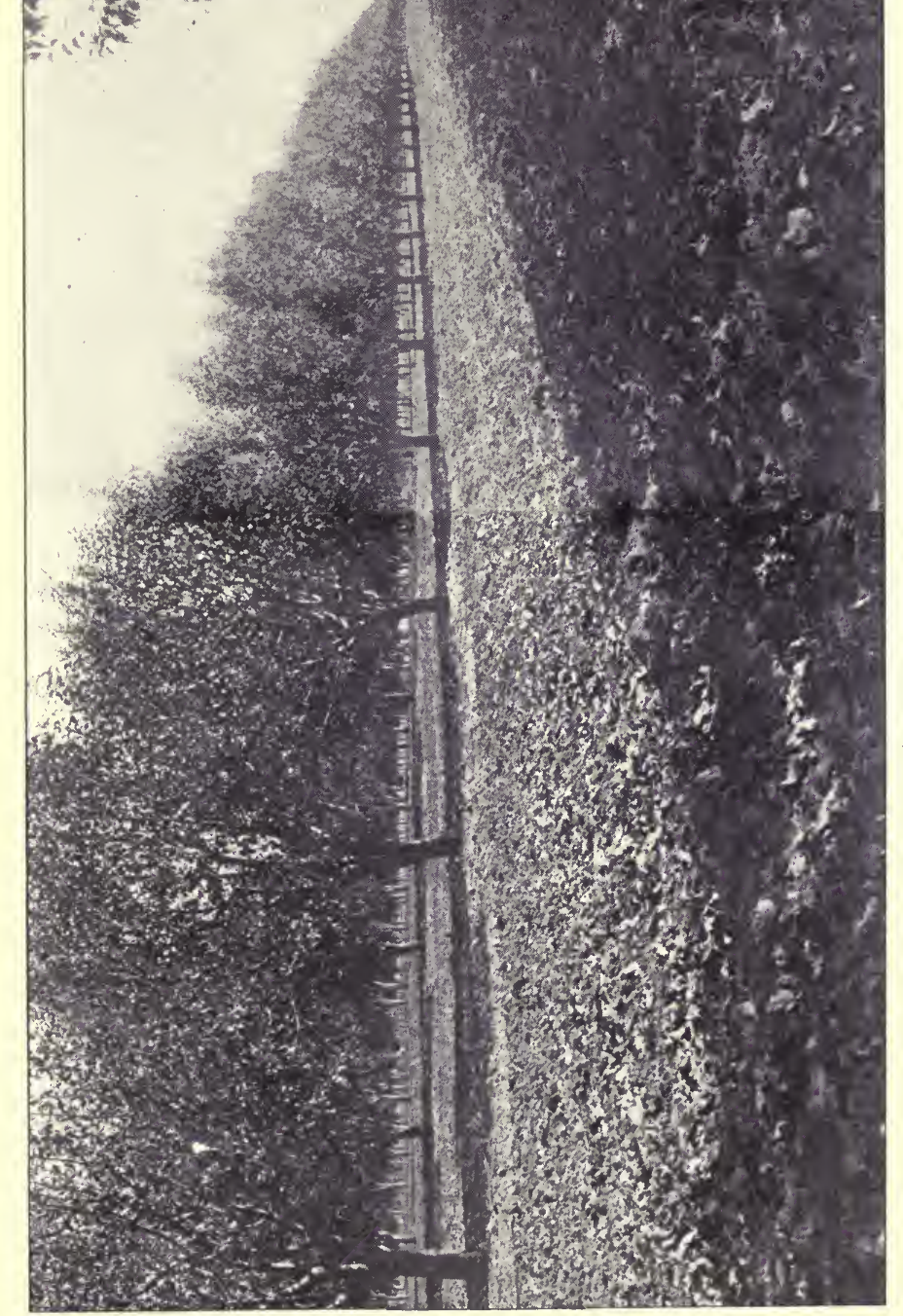

,

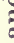

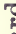

ह

:्ञ

कृ

-

\%

范

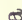

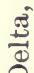

A

$\frac{8}{8}$

竞

द

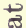

군 



\section{Experimental Results}

It has been claimed that the greatest injury to the trees from the application of arsenicals was through their corrosive action in destroying the bark at the base of the trees. In order to test this experimentally as well as the possibility of the tree absorbing sufficient free arsenic through its roots to cause systemic poisoning, varying strengths of spraying compounds were applied to different Ben Davis trees. One set of trees received as much lead arsenate as would be required to protect them for ten years; another set for twenty years, and still another set with the amount required to protect trees for forty years. This would be approximately the amount applied to a tree during its entire life, as there are several years in which no sprays are applied at the beginning, and an occasional year in which there is no fruit and therefore.no application of spraying material. All of the trees matured their fruit in perfect shape and even in the case of the heaviest application, the leaves were not seriously burned. The material was applied in the form of a spray with sufficient water so that it ran down the limbs and trunk in streams and dripped off from every part of the tree on to the ground to such an extent that, while the tree was whitened, and remained so all summer, the ground under the entire head of the tree was so saturated with the arsenic as to appear mouldy white to a depth of three or four inches. All of this poison was applied at the regular spraying time in the spring and the trees were irrigated in the normal manner during the season. An examination made in the fall disclosed no apparent injury to the bark of the trees at the crown and the roots near the surface had a normal healthy appearance. Part of these applications were made where there were weeds, alfalfa, and strawberries beneath the trees, and even with the heaviest applications no injury was observed upon the vegetation.

It will be necessary, of course, to continue this experiment for a number of years before any definite conclusions can be drawn, but it would seem that if the arsenic in the soil is freed in sufficient quantities from a few years' spraying to seriously injure or kill a tree, that enough arsenic would be freed in one year under like conditions from the excessive amount applied in this case to show some injury.

In order to further test the corrosive action of the arsenical compounds, the various spraying mixtures were applied directly to the bark of medium sized limbs of bearing trees, and maintained in contact with these limbs for a period of forty-five days during the latter part of the growing season. These experiments will be repeated on a much larger scale the coming season and it will, of course, be neces- 
sary to study the effect for several years before it will be possible to give positive results.

Each spraying solution was applied in three strengths, double the normal, ten times and twenty times the normal strength. The double strength arsenate of lead produced no effect on the limb. The limbs upon which the two higher strengths of this solution were applied, showed a very slight burning on a few of the leaves soon afterwards, but the injury did not increase through the season.

The Kedzie arsenate showed no injury in any of the three strengths used.

Paris green in double strength showed no injury at all. The ten and twenty times normal strength caused a slight burning along the edges of the leaves.

A soluble arsenate (sodium arsenate) was also applied in three strengths, one-twentieth, the same amount, and twice as much as there would be of insoluble arsenic applied in the form of lead arsenate in a year of normal spraying. The two weaker strengths showed no injury at all. The double strength produced a browning of a few leaves early in the experiment but this did not increase and never became at all serious.

The above summary of the first year's work is, of course, in no sense conclusive but it would seem to indicate that the bark of an apple tree is not seriously affected by the normal spraying solutions even where they remain in contact with it for considerable times. The fact that the weaker strengths of the soluble arsenate produced no apparent injury is also quite suggestive because if the spraying solutions should fall into an alkaline soil at the base of the tree it is not likely that there would be more arsenic set free in a single season than was applied directly to the tree in this case, and therefore, if injury should be produced under the latter condition, some other factor would be necessary to account for the condition, other than the arsenic alone. And as alkali has killed thousands of trees where no arsenical sprays have ever been applied, it would seem natural to infer that the death of the trees, even where both substances were present, might be due, in a large measure at least, to the alkaline factor.

A number of other experiments have been earried on, such as growing various crops in soil taken from around the base of trees said to have died from arsenical poisoning; growing crops in soils in which large amounts of the different spraying solutions have been mixed, etc. Up to the present time, all of the results tend to confirm the conclusions drawn in the cases cited above. 
The chemical examination of the orchard soils and of the trees for alkali and arsenic have not been completed, but the results so far are almost uniform in showing very small amounts of arsenic in the trees, from soils that are low in alkali, while all examinations so far in which a comparatively large amount of arsenic was found in the trees, have been from localities in which the alkali was so abundant in the soil as to be in itself a menace to orcharding.

\section{Conclusion}

While no definite conclusions can be drawn from these preliminary investigations as has already been suggested, it would appear that the injury to the apple trees in the western country may have a number of different causes. The evidence that alkaline seepage alone is sufficient to cause the death of fruit trees seems to be conclusive. The fact that the only places in which Jonathan trees are found to be dying in any numbers, where other trees similarly situated are not, are on areas underlaid with marl, suggests very strongly that there is some relation between that condition and the death of this variety of trees. The loss of a number of trees that have not been sprayed, in different sections where the alkali is apparently not present in sufficient quantities to be the killing agent, and the further fact that only the Ben Davis-Gano type are killed under such circumstances, indicates that we have a further factor to be considered, which we are at present calling "collar rot." That free arsenic if present in sufficient quantity will kill fruit trees has never been questioned, but the fact that all over the country the orchards which are located on suitable soils free from the other conditions mentioned, are showing no injury even where heavily sprayed for long periods of time, would seem to warrant the conclusion that has been previously stated by the senior author, that arsenical poisoning cannot be the primary cause of the death of the greater portions of our fruit trees. That where alkali is present in any quantity it is probable that the arsenic of the spraying solutions will be set free and will assist in the injury to the trees, but.the question whether the alkali would be strong enough in this case to destroy the orchard within a few years without the other factor, is a problem yet to be solved.

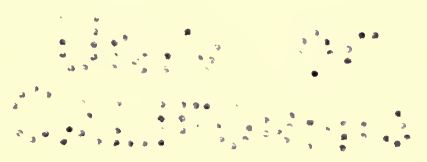


THIS BOOK IS DUE ON THE IAST DATE STAMPED BELOW

AN INITIAL FINE OF 25 CENTS WILL BE ASSESSED FOR FAILURE TO RETURN THIS BOOK ON THE DATE DUS ON THE FOURTH WILL INCREASE TO 50 CENTHE SEVENTH DAY DAY AND TO $\$ 1.00$ OVERDUE.

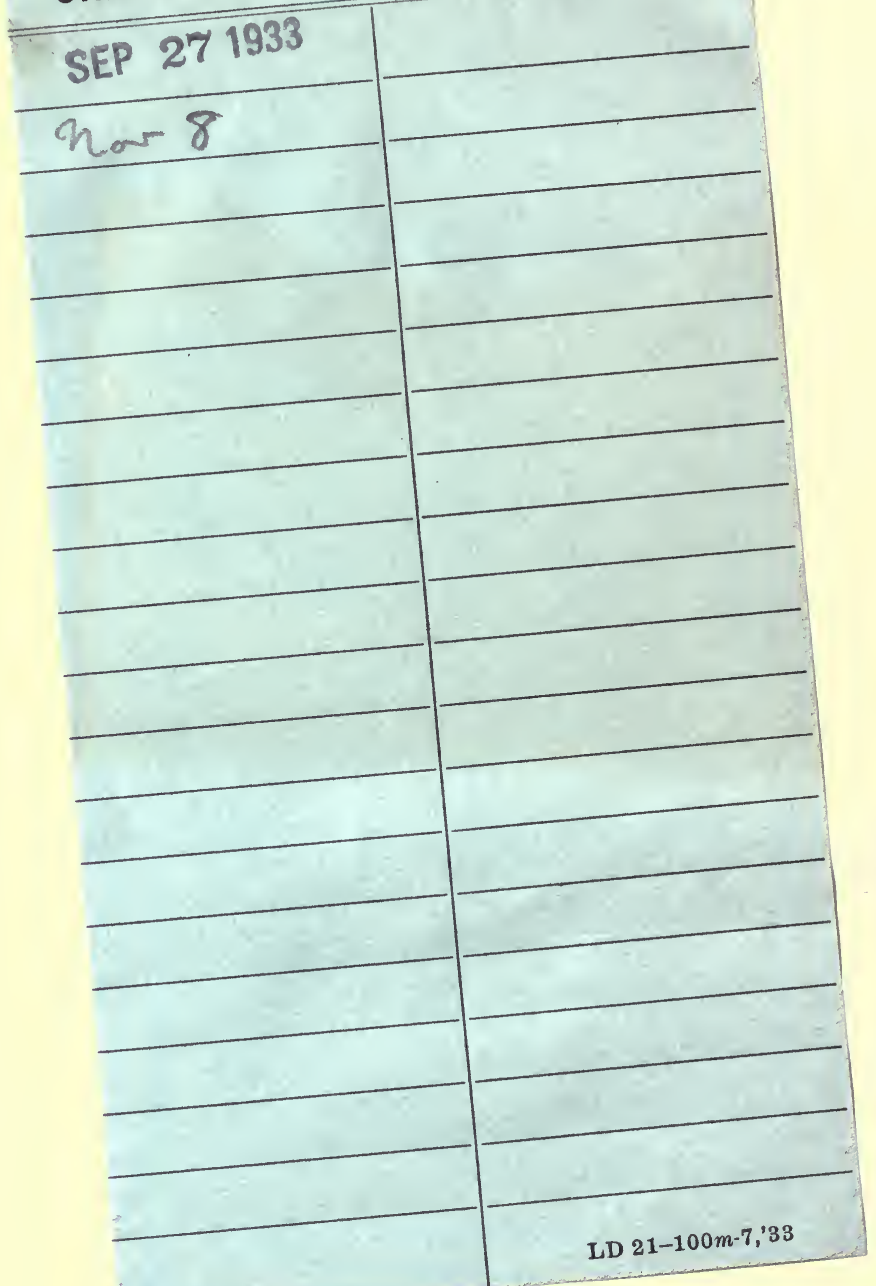


Makers

Syracuse, N. Y.

PAT. JAN. 21, 1908

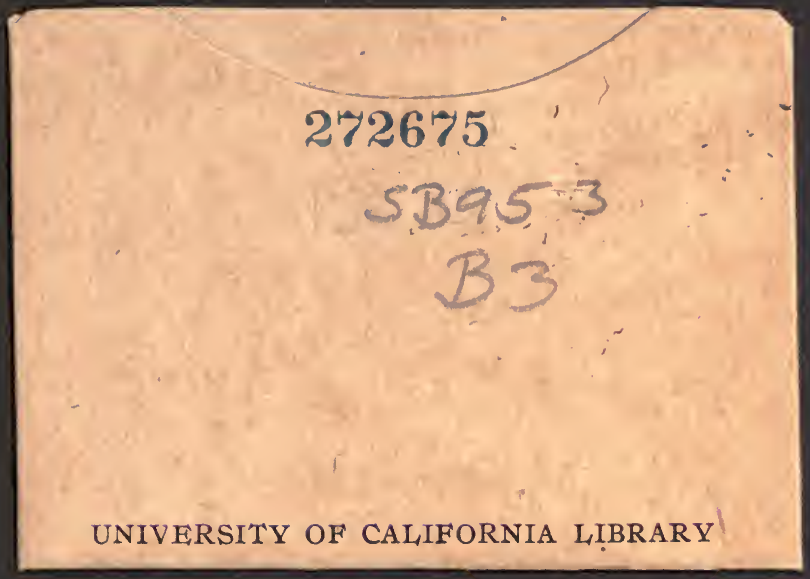


Sar?

(4)

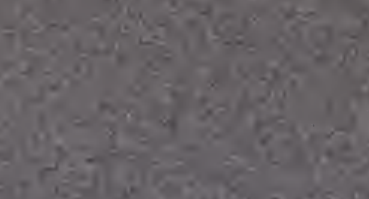

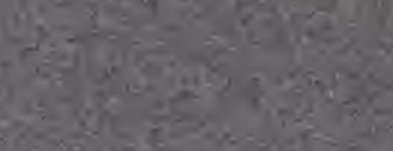

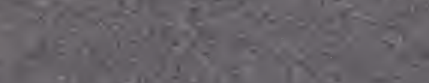

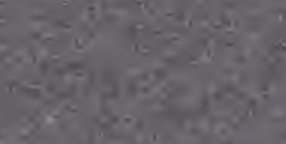
P.

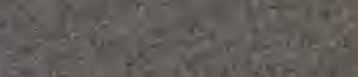

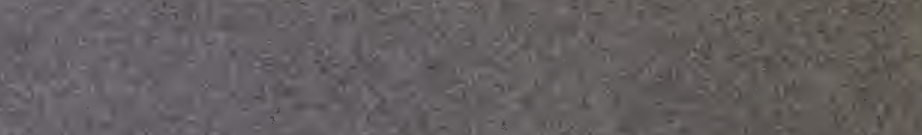

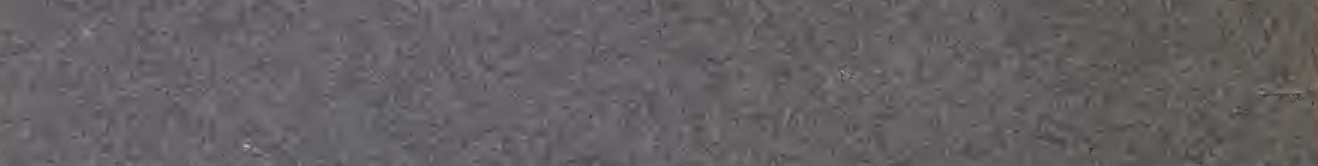



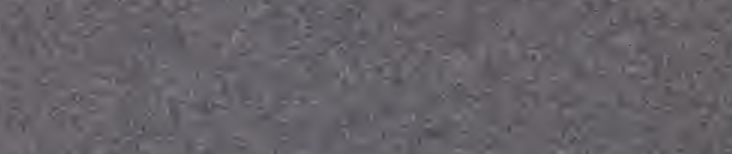
18 aste 3

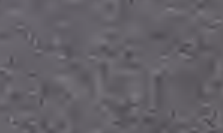

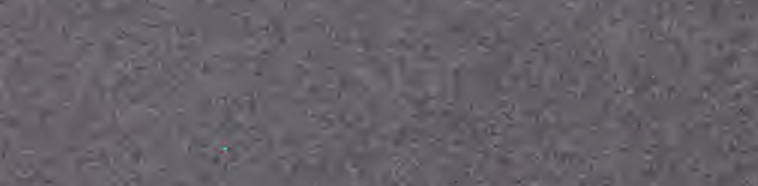

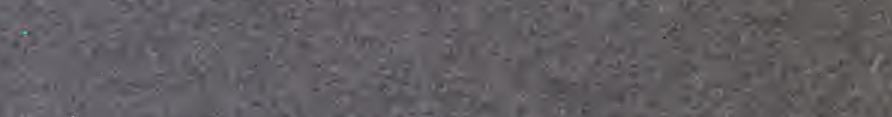



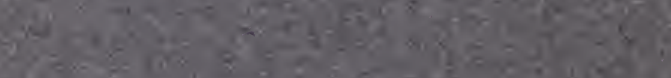
is

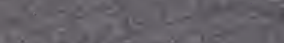

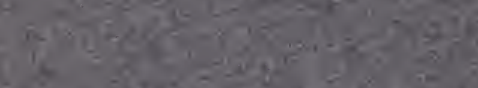

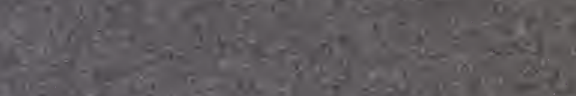

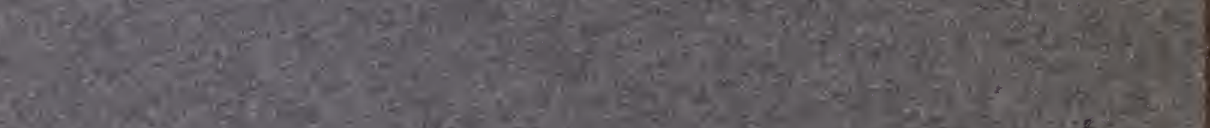

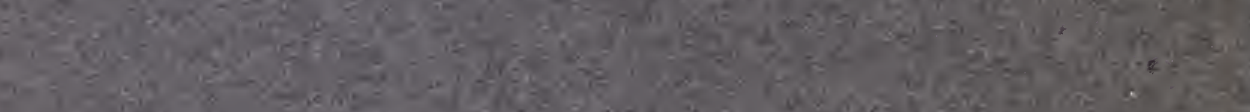

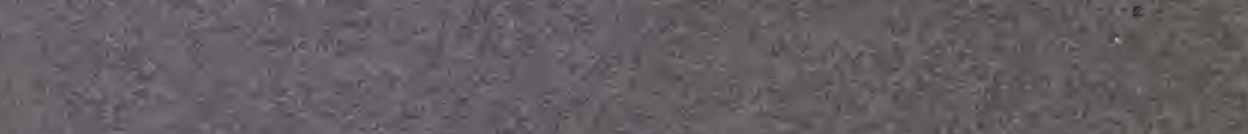

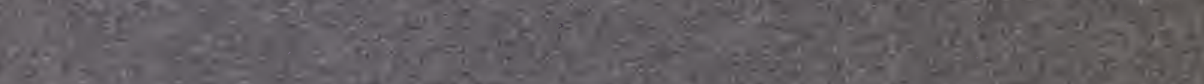
as? 3 in

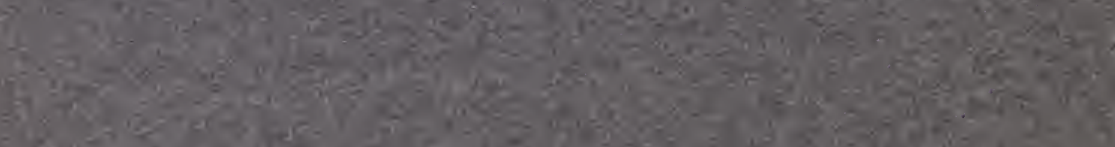

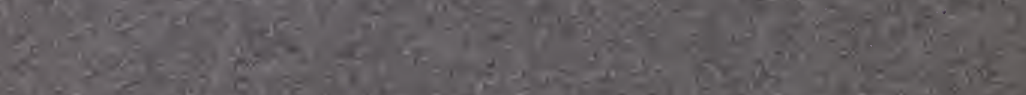

